\title{
AN INFLUENCE OF ICT INTEGRATION FOR EMPLOYEE POSITIONING THROUGH GLOBAL POSITIONING SYSTEM BY HUMAN RESOURCE MANAGEMENT DEPARTMENT IN THE ORGANISATION
}

\author{
Dr. SARITA A. DHAWALE
}

Head, Department of Computer Applications, Ashoka Center for Business and Computer Studies,

\author{
Nashik, Maharashtra, India
}

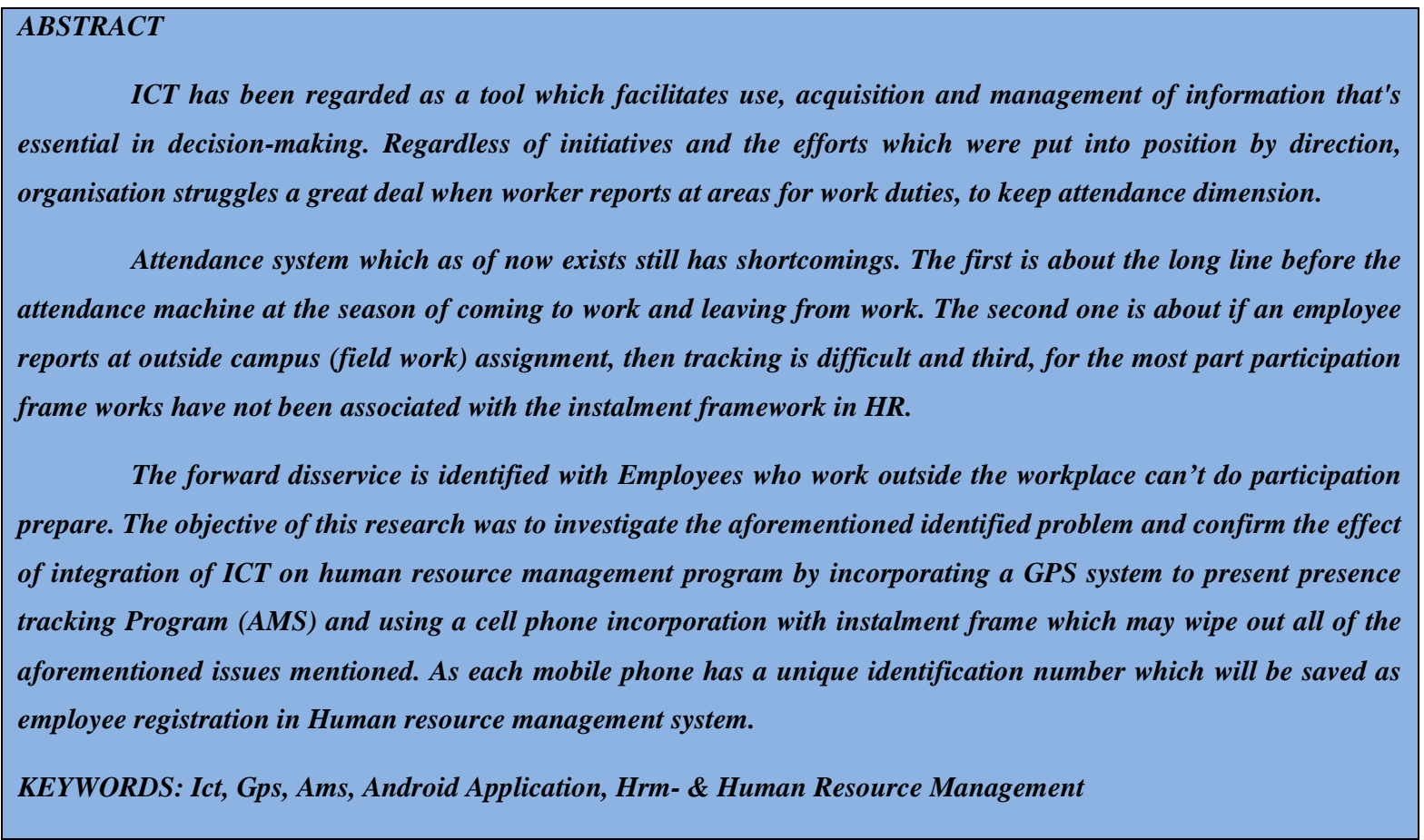

Received: Feb 25, 2019; Accepted: Mar 15, 2019; Published: May 04, 2019; Paper Id.: IJHRMRJUN201912

\section{INTRODUCTION}

Info and Communication Technologies (ICTs) have revolutionized management of businesses, [1] bringing forth new ways of doing things innovatively and efficiently. In a simple fact which makes ICT a tool in the business world of today.

[2] Notes that ICT integrated systems such as the Human Resource Information System (HRIS) allow businesses to conserve profile of staff -their private data Together with device identification- i.e. mobile phone information - so as to record the data in the server for attendance monitoring system, hence ensuring that organisation have attendance measurement system establish even though the person has reported to multiple locations some times for work assignments.

The capability requires integration of HR information. Therefore, with all these requirements, organisations need strong ICT solutions which would enable them to quantify the human resource function in 
functionality data. The most frequent advantages of ICT include enhanced accuracy of data, its own timer and fast supply, in addition to saving of worker's time to maintain queues for biometric presence. Similarly, mentioned reasons which justify ICT should be used by organizations as: raising and presenting an attendance program using GPS on the phone.

Currently the fingerprint attendance system in many of organisations is a biometric participation calculation that utilizations finger impression identification technique. This biometric fingerprint attendance system was presented and utilized since 1997. Designers and makers of this innovation understand that each human has distinctive fingerprint gesture. Truth be told, even indistinguishable twins have diverse state of fingerprints. This is incorporating the fingerprint into attendance machine. In any case, they don't know about the downside of a long line before the machine.

Attendance system has been known since antiquated time. In the first place, attendance system utilizing just paper and performed physically by signing a name on recorded register. Now a day fingerprints scanner has been used to save attendance records. It hasn't been clear GPS is going to be gained in their management procedures. It's in this context that this research sought to fill this gap in understanding by exploring the effect of integration of ICT in human resource management in business and allow workers to examine multiple places and document presence through the cellular system by maintaining GPS on into the apparatus.

\section{OBJECTIVE OF THE STUDY}

The following was the research objective:

- To determine integration of ICT's effect.

- To record attendance in AMS through Mobile phones when employee is on field work.

\section{RESEARCH HYPOTHESES}

- The study addressed the following research hypothesis

- H0: There is no impact of integration of ICT in human resource

- Direction in business for AMS.

\section{RELATED WORK}

In this segment, investigation of relative advancement has been used to register all the employees for AMS. For instance, attendance management utilizes username and passwords for verification. The administrator confirms the username, password and individual data, mobile id. Geo-locationing is the first way to provide location-based service. The widely used location technologies are like Global Positioning System (GPS), Wi-Fi, Cellular Network and Radio Frequency Identification (RFID). In the above study we have used GPS location along with application software to register the employee data in the server.

\section{METHODOLOGY}

- This study adopted a descriptive survey research design.

- This study designed a system to get attendance when employee is outside or on fieldwork. 
The target population included of administrators and all of the workers at Ashoka Education Foundation. It's therefore and private sector when worker keeps on movement for work were sampled to take part in the analysis.

User authentication is among the things in the system. Every worker is authenticated based on user identification number. This identification number is. The identification number in addition to other data is stored in every employee's apparatus.

In the beginning worker must put in the system APK documents in their device that is android. On when the system ran, mobile location service needs to be. If location service is the process won't go. Mobile location service will help to trace the worker's place. After the worker enters the job campus or beyond the campus area, android apparatus of the worker is mechanically joined to the office net and a message is delivered to the workplace sever with the worker identification and local time of this system that's counted as a login period of the worker. When a worker leaves the workplace space, employee will sign to assign time that is routed to the host together with worker identification out. Figure 1 depicts the system that lists AMS for each worker when enters within an organisation's methodology.

After the worker enters for work mission in any other campus or beyond the campus area, android apparatus of this worker needs to be signed into get on the office net and via GPS system place address will be shared into the workplace sever with the worker identification and local time of this system that's counted as login period of the worker. Worker will input in organisation sign in to find through GPS for campus entrance into the place after work done. Figure 1 depicts the system for campus reporting system's methodology

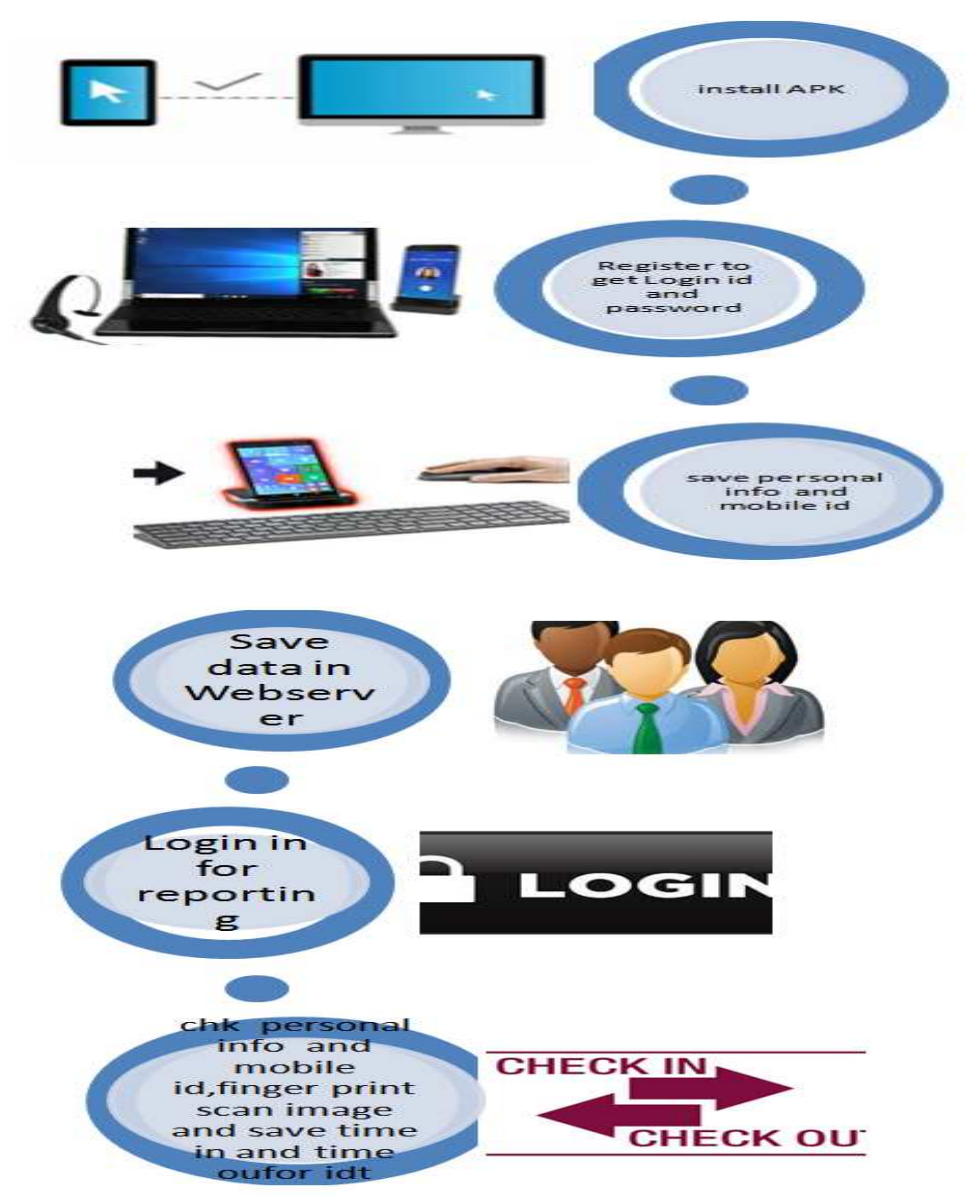

Figure 1: Flow of Operation for the Proposed System 


\section{SYSTEM OVERVIEW}

The systems supply a remedy to on-site presence occurring problem. This program is a Biometric attendance program utilizing GPS for mobile relies on the idea of internet services that's employed within a program that is mobile. The worker must set up the APK files created in their apparatus for them. In the beginning it's very important to conserve by entering the latitude, longitude and radius of region, the organisation coordinates. The employee must conserve the IP (internet protocol) address of their workplace net. One worker can save their data through this App's menu. This presence system logs your own login and logout time and finds your location. Since the worker enters his office area, the machine sends the worker identification and time that is local into the host and connects to the workplace net. Then the host stores the info in a database and receives the time. To conduct the system it's essential that organisation host and worker apparatus is at precisely the online connection.

\section{SYSTEM DESIGN}

The Biometric authentication-based attendance system using GPS for smart phone is a client-server approach and follows specific hardware and software architecture. Integrating the hardware and software is the main challenge here and the hardware and software works together.

\section{SOFTWARE ARCHITECTURE}

The software architecture Includes: The database, the host along with the application app.

- Database: The database is made up of range. We utilized SQL server database that's easy and efficient and can save a great number of documents and requires a configuration that is tiny.

- Program: The software program is designed using programming language. The application program offers organisation host and employee with the user interface. Programming in Android is easy, user android and friendly provides a great data.

- Server: The server is set up on the computer using apache-Tomcat7 that is private.

Tomcat7 is strong, free and simple to deploy.

\section{HARDWARE ARCHITECTURE}

This Biometric attendance method utilizing GPS for phone's requirement is an apparatus, which will operate the program, with the assistance of which the worker choose their own logout time with no hassle and will indicate their presence. The requirement is a computer.

\section{RESULTS AND DISCUSSIONS}

This analysis sought to ascertain the effect of ICT integration. The objective has been measured in two levels: The levels of perceptions from government authorities, workers and resource division s government. The findings about the senses of HR depts that are employees and were very favorable node. The system suggested relies on efforts in respondents, discovered the fitting of information saved percentage of respondents in our databases compare to finger printing. The table revealed that our proposed finger algorithm may be utilised within our system.

SOLUTIONS: Screen Shot for APK Matching fingerprint 

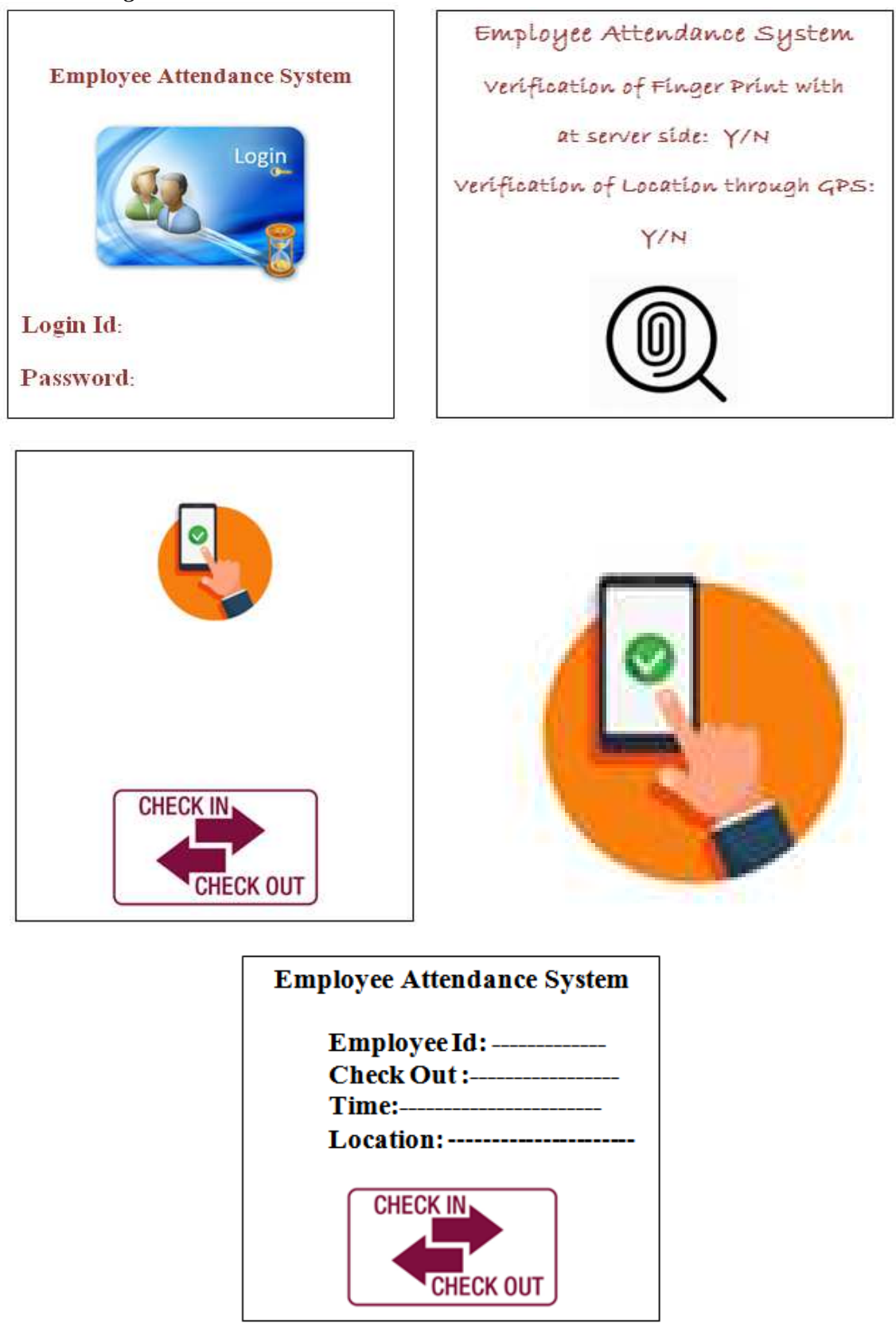

Figure 2

There Are Menus on the Screen Software as Shown in Figure

When users wish to utilize this program the user and device information need to be enrolled in the employee program on the other hand, when the user hasn't registered, it may pick the registration menu type as displayed in figure.

The consumer needs to active the finger on their apparatus or they could connect to the fingerprint scanner if the devices don't have fingerprint scanner. Press a button which will send the information capture apparatus along with a fingerprint scan results into the machine and place his finger, the server send the answer returns the apparatus and then will check whether the apparatus has been registered or not. 


\section{CONCLUSIONS}

- Finger print to perform identification worker and can be socialized with technologies and GPS to make an attendance software.

- Using image segmentation can nevertheless optimizes fingerprint. Change pixels and compare centered so it accelerate and may expedite procedure. A Few of the methods Which Can Be eliminated to maximize the fitting time would be the search management and Method of discovering fingerprint Tiles Detail/minute as fingerprint ridge bifurcation and finish.

- Our proposed system can resolve the Problems That came up in normal lack or presence system like the queue in front of the finger, the lack data Aren't incorporated with Human Resources Systems, the workers who work outside the workplace that Cannot do presence, and cheating (The worker requesting friends to fulfill the presence his buddy )

- The lack system can save yourself the charge since the worker will utilize their apparatus to do the presence, to supply and take care of the finger

Figure. Display to perform fingerprint

\section{LIMITATIONS}

To conduct the system it's essential that organisation host and the worker device is at precisely the online connection.

\section{REFERENCES}

1. Acosta, F. R. (2004). Information Technology Strategic Planof Olivarez Organisation.

2. Unpublished Doctoral Dissertation,University of Baguio, Philippines.Benfano Soweto, Ford Echo Simanjuntak, Fergyanto E. Gunawan, "Attendance System on Android Smartphone", IEEE, 978-1-4799-8975-1/15/\$31.00@2015.

3. Shraddha S. Chawhan, Mangesh P. Girhale, Gunjan Mankar, "Mobile Phone Based Attendance System", IOSR Journal ofComputer Engineering (IOSR-JCE), Volume 10, Issue 3, PP 48-50 (Mar.Apr.2013).

4. Mouli, G. C.,\& Viswanath, J. Effects of Employee Occupational Self-Rejections on Talent Management: A Study of Personality Factor role in Performance Evaluation ISSUES.

5. Freya.J. Vora, Pooja.L. Yadav, Rhea.P.Rai, Nikita.M.Yadav, "Android Based Mobile AttendanceSystem", International Journal of Advanced Research in Computer Science and Software Engineering (IJARCSSE), Volume 6, Issue 2, February 2016.

6. Ashwin K.1, Aswin Perumal A.2, Krishnakumar S.3, Maheshwari M.4, "RFID Based Employee Attendance and Monitoring System”, International Journal of InnovativeResearch in Computer and Communication Engineering (IJIRCCE), Vol.3, Special Issue 1, February 2015. 